\title{
Pulmonary valve agenesis-tetralogy of Fallot-absence of ductus arteriosus syndrome
}

INSERM

\section{Source}

INSERM. (1999). Orphanet: an online rare disease and orphan drug data base. Pulmonary valve agenesis-tetralogy of Fallot-absence of ductus arteriosus syndrome.

ORPHA:101206

Pulmonary valve agenesis-tetralogy of Fallot-absence of ductus arteriosus syndrome is a rare congenital heart malformation characterized by a tetralogy of Fallot (pulmonary stenosis, overriding aorta, ventricular septal defect and rig ht ventricular hypertrophy), complete absence or rudimentary pulmonary valve that is both stenotic and regurg itant and an absence of the ductus arteriosus. It presents prenatally with cardiomegaly, polyhydramnios, fetal heart failure, hydrops fetalis and fetal demise or postnatally with cyanosis and respiratory failure due to bronchomalacia secondary to bronchial compression from dilated pulmonary arteries. It is frequently associated with 22 q11 deletion. 